\title{
EL ARTE DE IFRĪQIYA Y SUS RELACIONES CON DISTINTOS ÁMBITOS DEL MEDITERRÁNEO: AL-ANDALUS, EGIPTO Y SICILIA
}

\author{
Clara Delgado Valero
}

U.N.E.D.

Varias son las manifestaciones artísticas de época islámica que vinculan a Túnez con al-Andalus, Egipto y Sicilia. Ya desde la Antigüedad, Túnez había actuado como vehículo transmisor entre Oriente y Occidente, tanto por su potencia cultural como por su posición intermedia en el Mediterráneo. Estas específicas condiciones debieron de favorecer el desempeño de una función similar durante la época islámica ${ }^{1}$. De ahí que no parezca extraño que una serie de manifestaciones artísticas, a las que se alude posteriormente, tengan en la Ifrīqiya aglabí su primer testimonio conocido. En cambio, resulta bastante singular y se carece de argumentos suficientemente contrastados para justificar la proyección de estas manifestaciones sobre determinados puntos del ámbito geográfico mediterráneo. Por lo tanto, en este momento, se trata de presentar una serie de cuestiones como vía de análisis de la cultura islámica en torno al Mediterráneo, donde si el papel de Túnez como foco emisor, y posiblemente creador, aparece con bastante nitidez, no lo son tanto las circunstancias que rodean los focos receptores.

Las manifestaciones documentadas que vinculan los focos indicados pertenecen a tres ámbitos diferenciados: el mundo funerario, la arquitectura religiosa y el ámbito palatino. A excepción de la arquitectura religiosa, de la que no existe testimonio en Sicilia debido, sin duda, a carencias documentales más que su inexistencia, las demás manifestaciones se hallan perfectamente representadas en todas las zonas analizadas.

1 Vinculaciones artísticas entre algunos de los focos citados, aunque ninguna de ellas se corresponde con las aquí analizadas, ya fueron estudiadas por: Terrasse, H., "Les influences infriqiyennes sur l'art de l'Espagne musulmane aux $\mathrm{x}^{\mathrm{e}}$ et $\mathrm{xI}^{\mathrm{e}}$ siècles", Revue Tunisienne, nouvelle série, 15 y 16 (1933), 251-262; Marçais, G., "Les échanges artistiques entre l'Egypte et les pays musulmans occidentaux", Hespéris, XIX (1934), 95-106. Ambas fueron recogidas por L. Torres Balbás en Al-Andalus, III (1935), 393-396 y 411-424. 
Por lo que se refiere al mundo funerario hay que destacar un tipo de estela sepulcral denominada cipo o columna sepulcral ${ }^{2}$. Su forma es cilíndrica, aunque a veces puede ser ligeramente troncocónica invertida y muy excepcionalmente semicilíndrica. La parte inferior está sin desbastar y la superior queda en resalte, estando recorrida generalmente por dos bandas incisas que pretenden simular una moldura. Entre ambas partes, y ocupando un sector de 120 grados aproximadamente, se desarrolla la inscripción que, en algunas ocasiones, va enmarcada por una orla geométrica o epigráfica.

La columna sepulcral aparece en los cuatro focos señalados (lám. 1a), si bien está documentada por primera vez en Qayrawān en el año 862. En esta misma ciudad se encuentra el mayor número de cipos conservados, formando un conjunto cuya datación corresponde al período comprendido entre el siglo IX y la primera mitad del siglo XI. Ahora bien, ni éste es el único punto de Túnez donde han sido hallados cipos, ni tienen idéntica cronología. En Monastir los cipos se documentan entre principios del siglo XI y el siglo XIV; en Gorjani están datados desde el último cuarto del siglo xIII a finales del siglo xv; mientras que algunas otras piezas procedentes de Susa y Sfax corresponden a los siglos XI y XII.

En al-Andalus, los cipos funerarios sólo tienen atestiguada su presencia en Toledo y su provincia durante el siglo XI. Semejante concreción espacial unida a la temporal hace de este grupo uno de los más singulares, cuyo primer testimonio documentado se fecha en el año 1001. Fuera del ámbito toledano sólo se conserva, de forma excepcional, un único cipo en la isla de Palma de Mallorca, con origen y cronología imprecisa, aunque pudiera datarse en la primera mitad del XIII.

En Egipto, las piezas que mantienen esta tipología provienen de

2 Respecto a este tema cf. Delgado Valero, C., «La columna sepulcral: una forma funeraria del arte helenístico y del arte islámicon, II Congreso de Arqueología Medieval Española, Madrid, 1987, 560-566, donde se recogen, además de los testimonios helenísticos, todo el repertorio de cipos islámicos documentados. Un estudio más detallado de los cipos toledanos fue realizado por esta misma autora en Materiales para el estudio morfológico y ornamental del Arte Islámico en Toledo, Toledo, 1987, 21-34, y en el catálogo. A todos los recogidos en ambos textos habría que añadir uno conservado en el Museo Mandralisca de Cefalú (Sicilia), otro en el Museo de Palma de Mallorca, publicado por G. Roselló Bordoy, Corpus Balear de epigrafía árabe, Palma de Mallorca, 1969, núm. 23, lám. XII y otro más hallado recientemente en las excavaciones de Calatrava la Vieja publicado por J. Zozaya, "Un cipo funerario procedente de Calatrava la Vieja", Boletín de Arqueología Medieval, 4 (1990), 311-320. 
Alejandría y del Delta. El ejemplar más antiguo se remonta al año 1015 si bien se conservan columnas sepulcrales hasta la mitad del siglo XIV.

El conjunto de cipos hallados en el sur de Italia presenta varias características, tales como la documentación de un menor número de piezas, su localización en Nápoles y Sicilia, así como su datación en los siglos XI y XII.

Con independencia de los cipos, existe dentro del mundo funerario otro elemento común atestiguado únicamente en Qayrawān y Toledo ${ }^{3}$. Se trata de un fragmento de poema funerario que dice: « $\mathrm{OOh}$ gentes! Yo tenía una esperanza que me impidió alcanzar la muerte.»

Así pues, a partir de estos datos se puede establecer la existencia de una manifestación funeraria perfectamente documentada que vincula a estos cuatro focos y cuya cronología no excede del siglo xv (fig. 1a). Su aparición se sitúa en Túnez a partir de la $2 .^{\mathrm{a}} \mathrm{m}$. del siglo Ix, si bien las únicas piezas documentadas con las que mantiene una analogía formal y funcional se hallan doce siglos antes en el Ática (lám. 1c). El silencio arqueológico que media entre este dilatado espacio y tiempo imposibilita establecer el vehículo de transmisión e incluso la propia transmisión desde un ámbito helenístico. Aunque, en cualquier caso, el único referente documentado tiene como fuente el mundo griego-helenístico.

Respecto a la arquitectura religiosa y dentro de las manifestaciones artísticas comunes, existe una tipología de mezquita localizada tanto en Túnez como en al-Andalus y Egipto. En Sicilia no existe, por el momento, ninguna construcción análoga debido, en parte, a las escasas mezquitas documentadas arqueológicamente. En este caso, se trata de un tipo de mezquita caracterizada por una estructura generalmente cuadrada, de pequeñas dimensiones, organizada internamente mediante cuatro soportes que conforman nueve tramos con cubierta abovedada o cupulada. A pesar de que esta tipología no se halla entre los modelos habituales utilizados por el Islam, cuenta con los suficientes exponentes espaciales y temporales para merecer su inclusión dentro de la arquitectura religiosa islámica. Siguen este esquema una nómina de unos 20 edificios cuyo primer exponente se halla en Túnez ${ }^{4}$ (figs. 2

3 Delgado Valero, C., Materiales..., núm. 104, que corresponde a un ladrillo funerario. M. Ocaña Jiménez me indicó la existencia de un fragmento análogo en Qayrawān que no he podido localizar y los correspondientes a los núms. 11 y 117 de sendas lápidas de su Repertorio de inscripciones árabes de Almería, Madrid-Granada, 1964.

${ }^{4}$ King, G., "The nine bay domed mosque in Islam", Madrider Mitteilungen, 30 (1989), 332-390, recoge una veintena de mezquitas desde los primeros tiempos del Is- 
y 3) en la mezquita de Bū Fațātā en Susa 5 construida por el emir aglabí, Abū 'Iqāl al-Aglab b. Ibrāhìm (838-841). Poco después y también en Túnez, aunque en este caso en Qayrawān, se documenta la mezquita de Tleta Biban ${ }^{6}$ o de las Tres Puertas (866). Más de un siglo después esta tipología aparece en Toledo en la mezquita de Bāb al-Mardūm fechada en 999-1000 ${ }^{7}$ y en la mezquita de Tornerías datada en la segunda mitad del s. XI ${ }^{8}$. Asimismo se encuentra en Egipto en el Mašhad Šarif Ṭabātabā de al-Fusțāṭ cuya datación según Creswell correspondería al año 943, mientras que King considera que pertenece al siglo XI ${ }^{9}$. A ese mismo momento, período fatimí, adscribe King la tumba de los 77 Gobernadores o Saba ${ }^{\mathrm{c}}$ wa-Sab în Wālī en Aswān y la mezquita al-Fiyala de Fusțāt ${ }^{10}$.

Todas estas mezquitas tienen como características comunes: el tamaño, la planta, la proliferación de cubiertas independientes y el deseo de una buena comunicación con el exterior. Otra nota común es la utilización del ladrillo como material favorito. En cambio sólo tres, y más concretamente las mezquitas de Bū Fațāta, de Tetla Biban o de las Tres Puertas y la de Bāb al-Mardūm, presentan una fachada de triple arcada sobre la que discurren bandas con motivos decorativos y frisos epigráficos.

Buena parte de las mezquitas que siguen este esquema han sido da-

\footnotetext{
lam hasta el siglo xvı, encabezados por la mezquita de Bū Fațāta en Susa. La difusión de este modelo supera el marco del Mediterráneo desde el primer momento, como lo demuestra la mezquita de Balj conocida como la Haŷŷ̃ Piyād-i o también como Masŷid-i Ta'rij o Nuh Gunbad en Afganistán. En este último caso, al carecer de testimonios documentales, su cronología oscila según los diversos autores entre los siglos Ix y xI, si bien L. Golombek, "Abbasid mosque at Balkh", Oriental Art, 3 (1969), 188-189, la fecha en la primera mitad del Ix y por tanto coetánea, e incluso anterior, a la mezquita de Bū Fațăta en Susa. Dentro de la órbita de Balj se hallan dos ejemplos más, datados en los siglos x y xi: Chahar Șuṭūn en Tirmīd y la mezquita Diggarān en Hazāra, cerca de Bujāra.

5 Creswell, K. A. C., Early Muslim Architecture, II, Nueva York, 1940, 246-248; Marçais, G., L'architecture musulmane d'Occident: Tunisie, Algérie, Maroc, Espagne et Sicile, París, 1954, 24-25.

6 Creswell, K. A. C., op. cit., pp. 325-326; Marçais, G., op. cit., pp. 25 y 47-48. Lézine, A., "Le plan ancien de la ville de Kairouan", Notes d'archéologie ifriqiyenne. París 1968, p. 67.

7 Ewert, C., "Die Moschee am Bab Mardum in Toledo", Madriger Mitteilungen, 18 (1977), 287-354; Delgado Valero, C., Totedo islámico: ciudad, arte e historia. Toledo, 1987, 283-303 y 350-351.

8 Delgado Valero, C., op. cit., 303-317 y 351-352.

9 Creswell, K. A. C., Muslim Architecture of Egypt, I. Oxford, 1952, 11-13; G. King, op. cit., 345-351.

10 Ibidem, 351-356.
} 
tadas con diferencias cronológicas notables, fundamentalmente por Golombek y King (fig. 1b) quienes se han ocupado especialmente de este modelo tipológico. Pero estas diferencias de criterio también afectan a otros aspectos, tal vez más relevantes, como el de su función y origen. A este respecto, Creswell atribuye a estas construcciones un carácter de estructuras funerarias cuyo primer testimonio se hallaría en el octógono de la Qubbat al-Sulaybiya en Sāmarrā' ${ }^{11}$. Lézine, por su parte, propone la función de oratorio que, en el caso tunecino, estaría asociada a un ribat ${ }^{12}$. Ettinghausen ${ }^{13}$ considera el frigidarium de Jirbat alMafŷar el precedente de este tipo de mezquitas que, por lo tanto, tendrían su origen en la sala de recepción asociada al baño. Pero, teniendo en cuenta que en esta sala se celebran recepciones y audiencias principescas y califales, King ${ }^{14}$ toma esta idea como punto de partida para otorgar a estas construcciones una connotación honorífica extensible a otros edificios concebidos con similar función. De esa forma busca, y halla en la mayoría de los casos, la asociación de cada una de las mezquitas con un personaje prominente de la sociedad y la religión, bien sea como construcciones aisladas o en relación con una tumba reverenciada. Sin embargo, siendo una explicación plausible, no hay que olvidar que tras la construcción de cualquier edificio de carácter piadoso siempre se halla una figura relevante que lo costea para el bien de la comunidad, con lo cual siempre hay implícito un cierto carácter hono-

11 Creswell, K. A. C., Early Muslim Architecture, II, 283-286. También sobre la aparición de tumbas monumentales en el Islam, cf. Grabar, O., "The earliest islamic commemorative structures, notes and documents", Ars Orientalis, VI (1966), 7-46.

12 Lézine, A., "Les mosquées voûtées de l'école aghlabide de Sousse», Notes d'archéologie ifriqiyenne, París, 1968, p. 81, donde establece la semejanza de Bū Fatāta con el pequeño oratorio de la Sayyida cuya excavación demostró ser la mezquita de un ribat. A esta hipótesis añade el hecho de que están atestiguados documentalmente la existencia de varios ribats en Susa y sus alrededores.

13 From Byzantium to Sasanian Iran and Islamic World, Leyde, 1972, 57-61. Recoge asimismo su paralelismo formal con las iglesias de nueve tramos con ejemplo en el oratorio de Germigny-des-Prés, fechado en 806, remitiendo a K. J. Conant, Arquitectura Carolingia y Románica, 800/1200, Madrid, 1991, 50-53, quien a su vez remite a modelos orientales cuyo precedente formal se encontraría en el pretorio romano de Phaena (Musmieh, cerca de Damasco), anterior a 169 d. C. En cualquier caso y con independencia de este precedente en el arte cristiano, las plantas centralizadas y no exclusivamente de nueve tramos, inician su conformación en época constantiniana reaprovechando edificios funerarios en honor de los héroes de la Antigüedad al objeto de venerar monumentalmente los lugares sagrados de los mártires (martirya). De forma que este modelo condicionará durante el medievo la aparición de dos tipologías arquitectónicas: la iglesia funeraria y la capilla privada-relicario.

14 Op. cit., 385-389. 
rífico hacia su fundador. $\mathrm{Al}$ mismo tiempo, tampoco puede considerarse como el modelo habitual de mezquita asociada a una tumba reverenciada dado que están documentadas diversas tipologías. Por todo ello, puede decirse que, por el momento, no existe una explicación completamente satisfactoria sobre la función de este tipo de mezquitas en el Islam.

Existe, en cambio, una relativa unanimidad sobre los orígenes de esta tipología. A excepción de Golombeck ${ }^{15}$, que la considera un modelo de Asia Central o tal vez de Mesopotamia, la mayoría de los autores coinciden en un origen más próximo al Mediterráneo ${ }^{16}$. En este último caso se halla Ettinghausen que lo sitúa en la sala de audiencia de Jirbat al-Mafŷar (fig. 3c). Godlewski localiza el precedente de este tipo de construcción en el Magnaura o Salón del Trono del Gran Palacio Imperial bizantino de Constantino, del siglo Iv d. C. A su vez King opina que esta tipología pudo entrar en los repertorios islámicos en un estado formativo procedente de al-Mafŷar o de cualquier otra fuente de importancia similar localizada en algún lugar del área central del mundo islámico. Es esta última adscripción, sin duda, la menos comprometedora, y tal vez por ello la más eficaz, puesto que justificaría un origen en el mundo tardo-antiguo, lo cual parece indudable, evitando la primogenitura entre Occidente y Oriente; en definitiva entre Bū Fațāta y Balj, con sus consiguientes focos de irradiación. Sin embargo, es curioso que en este estado formativo no se incluya la mezquita del Qașr alHallābāt ${ }^{17}$ atribuida al califa Hišām entre los años 709-743. Sus dimensiones internas de 10,70 por $11,80 \mathrm{~m}$, su carácter abierto con entradas situadas en los lados $\mathrm{S}$, E y O, la existencia de pórticos rodeando el edificio confirman una tipología (fig. 3d) que, posiblemente, logra su plena definición con abovedamientos diferenciados y utilización del ladrillo un siglo después en Túnez.

Por último y respecto al ámbito palatino hay que destacar la existencia de un tipo de organización caracterizada por un estanque o alberca de grandes dimensiones, a la que suele asociarse una estructura o

15 Cf. op. cit., p. 188

16 Ettinghausen, R., op. cit., 57-58; Godlewski, W., "The mosque building in Old Dondola", New Discoveries in Nubia: Proceedings of the Colloquium on Nubian Studies. La Haya, 1979 (ed. P. Van Moorsel, Leyden, 1982), 21-28; King, G., op. cit., p. 390.

17 Bisheh, G., «Excavations at Qasr al-Hallabat, 1979», Annual of the Department of Antiquities of Jordan, XXIV (1980), 73-75, otro posible nexo en común es una inscripción cúfica de la que no indica su lugar de ubicación en la mezquita y que recoge una fórmula piadosa "Oh Dios, perdona a tu siervo, Yãbir hijo de..., cliente de...". 
pabellón rectangular. En estos lugares parecen conjugarse ciertas funciones de recepción con otras de recreo y con actividades agrarias.

La existencia de conjuntos palatinos con gran estanque cuenta con abundantes testimonios en el arte oriental tardío, utilizándose en sus descripciones términos como "Lago" o "Pequeño Mar» ${ }^{18}$, en clara alusión al tamaño de sus estanques. En Occidente islámico este tipo de esquemas no parecían habituales, si bien cada vez se están documentando un mayor número de ellos, fruto tanto de la localización de nuevas estructuras como de la revisión de yacimientos antiguos, lo que está conduciendo a que se perfilen como otro esquema organizacional en las construcciones de carácter aúlico. Concretamente en los ámbitos aquí analizados está atestiguada su existencia en cada uno de ellos: Túnez, al-Andalus, Sicilia y Egipto.

Nuevamente el testimonio más antiguo documentado que responde a este esquema tipológico se halla en Túnez. Se trata del Qaṣr al-Bạ̣r o Castillo del Lago en la ciudad de Raqqāda, a $8 \mathrm{~km}$ al S de Qayrawān, comenzada por el emir aglabí Ibrāhīm II a partir del año 876. En ella el emir Ziyãdāt Allāh construyó en 903-909 un famoso estanque al cual aludía Ibn al-Abbār con estas palabras: "Cuando subió al trono Ziyādāt Allāh III... cavó un hoyo en el que construyó un estanque de 500 codos y 400 de ancho conectada mediante una acequia. Y llamó a este estanque al-Bahr (el Lago) y en este sitio levantó un castillo al que llamó 'Arūs (el Desposado). Estaba construido sobre cuatro niveles y se gastó.... ${ }^{19}$. La espectacularidad del estanque, según al-Bakrī, hacía exclamar al Mahdī fatimí que en Ifrīqiya había visto dos cosas sin parangón en Oriente: la gran cisterna situada en la puerta de Túnez en Qayrawān y el castillo de Raqqāda conocido como el castillo del Lago ${ }^{20}$. Por desgracia, de esta construcción, cabeza de serie de un grupo, sólo existe una breve descripción en la que se indica que, tangente al exterior del estanque, en uno de los lados cortos situado al occidente, se levantaba una estructura rectangular de 16,60 por $9,25 \mathrm{~m}^{21}$.

Un esquema similar presentan construcciones levantadas en esta 83.

18 Wilber, D. N., Persian gardens and garden pavilions. Washington, 1979, 13, 52, 57,

19 Chabbi, M., «Raqqada», Africa, II (1968), p. 392.

20 Marçais, G., op. cit., p. 28.

21 Ibidem, p. 28; también sobre este palacio cf. Lézine, A:, "Sur deux châteaux musulmans d'Ifriqiya: Raqqada-Ajdabiya", Revue des Études Islamiques, XXXIX/1 (1971), 87102. 
misma zona entre finales del x y el siglo xI, tales como Sabra-Manșūrīya y el Dār al-Baḥr en la Qal'a de los Banū Hammād. La primera ciudad se halla a un kilómetro y medio al S de Qayrawān y en ella existe un gran estanque de $130 \mathrm{~m}$ por $50 \mathrm{~m}$ adscrito a época fatimí o zirí ${ }^{22}$. Más precisas son las referencias al Dār el Baḥr o palacio del Lago de la Qal‘a, perteneciente a la primera dinastía local argelina (s. XI). El palacio se caracteriza por contar con un vasto patio porticado ocupado por un gran estanque donde se celebraban fiestas náuticas según el autor del Kitāb al-Istibșār ${ }^{23}$. El estanque de 64 por $45 \mathrm{~m}$ estaba rodeado por construcciones (fig. 5a). La parte central del sector $\mathrm{N}$ está ocupada por una estructura rectangular compuesta por tres estancias, mayor la central que las laterales, comunicadas entre sí y abiertas al patio cuya disposición recuerda a las salas de recepción. En cambio, el sector O adquiere un mayor desarrollo aunque posiblemente vinculado a recepciones o ámbitos más privados. Tanto es así que de las tres salas que lo componen, las dos extremas son de medianas dimensiones y comunican con el patio del Lago, mientras que la central, situada entre ellas, es más amplia (19 por $15 \mathrm{~m}$ ), pero se abre a un segundo patio dispuesto en eje con el del Lago ${ }^{24}$.

Bajo los hafsíes también se continuó atribuyendo a estos grandes estanques una función de recreo como lugares de divertimento náutico. Así lo señalaba Ibn Jaldūn sobre el jardín de Abū Fihr, creado por el califa al-Mustanșir (1249-1277) a un kilómetro al S de Ariana en los alrededores del Túnez, el cual describía como un bosque de árboles... «En la mitad de este bosque un gran jardín servía de cinturón a un estanque tan extendido que parecía el mar. El agua llegaba allí por un antiguo acueducto. Llevadas por este conducto las aguas caían por una amplia boca en un aljibe cuadrado (que servía de estanque de decantación) y de allí, a través de un canal bastante corto hasta el gran estanque

22 Marçais, G., "Recherches d'archéologie musulmane en Tunisie», Bulletin de la Société française des Fouilles Archéologiques, (1924), 39-47, y L'architecture..., 80 y 81; Zbiss, S. M., "Mahdia et Sabra-Mansuriya: nouveaux documents d'art fatimite d'Occident", Journal Asiatique, CCXLIV (1956), 79-93; Terrasse, M., "Recherches archéologiques d'époque islamique en Afrique du Nord", Académie des Inscriptions et Belles-Lettres, novembre-décembre (1976), 590-611.

23 Obra anónima de geografía que reproducía la de al-Bakrī con significativas adi-

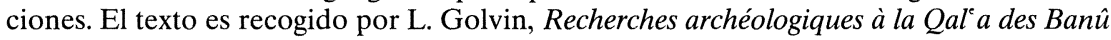
Hammad. París, 1965, p. 58, remitiendo a la traducción de Fagnan, L'Afrique Septentrionale..., p. 101.

${ }_{24}$ Golvin, L. op. cit., p. 58, en nota indica que G. Marçais da como dimensiones del estanque 78 por $35 \mathrm{~m}$ al medirlo desde el borde; Marçais, G., L'architecture..., 81, 82-84. 
al cual llenaban de olas agitadas. A cada extremo del estanque se levantaba un pabellón, uno grande y otro pequeño, cuyos techos están sostenidos por columnas de mármol blanco y por muros revestidos de marquetería de mármol» ${ }^{25}$. Este gran estanque rectangular medía 209 por $80,50 \mathrm{~m}$.

En otras ocasiones no existe ninguna referencia textual, siendo la tradición la que atribuye a que en estas grandes extensiones de agua se celebrasen verdaderas naumaquias. Así sucede con el estanque realizado al O de Tremecen por Abū Tašfin entre 1318 y 1336, cuyas dimensiones eran de 200 por $100 \mathrm{~m}$ alcanzando $3 \mathrm{~m}$ de profundidad 26 . En estos dos últimos casos, pero sobre todo en el primero de ellos, parece concretarse una trayectoria, posiblemente iniciada en los conjuntos anteriores, en la que los grandes estanques asociados a estructuras arquitectónicas se convierten en lugares que, pudiendo ser escenario de algunos actos protocolarios, se vinculan a actividades de recreo, bien lúdicas, bien de irrigación de un amplio parque. Posiblemente con este carácter se extendieron a Marruecos donde los mariníes realizaron en el jardín real de Fes el Ŷadīd ${ }^{27}$, propagándose a las ciudades imperiales de Mequinez, Fez, Rabat y Marrakech 28 con el nombre de Agdal.

En al-Andalus también se documentan, a partir del siglo x, estanques que presentan cierta semejanza con el modelo norteafricano ${ }^{29}$. El

25 Solignac, M., "Travaux hydrauliques hafsides de Tunis", Deuxième Congrès de la Fédération des Sociétés Savantes de l'Afrique du Nord, Argel, 1936, II, 528-17. La descripción del jardín en Ibn Jaldūn, Histoire des Berbères et des dynasties musulmanes de l'Afrique septentrionale, trad. de Slane, Argel, 1854, t. II, 337-338. Es recogida por G. Marçais, "Bustān", E.I., I (1960), 1386-87, en "Les jardins de l'Islam», Mélanges d'Histoire et d'Archëologie de l'Occident Musulman, 1 (1957), p. 237, así como en L'architecture..., $312-313$ y 327.

${ }_{26}$ Marçais, G., L'architecture..., p. 327, y Marçais, W. y G., Monuments arabes de Tlemcen, 126-127.

27 Bressolette, H. y Delaroziere, J., «El Mosara, jardin royal des Mérinides», Hespéris-Tamuda, XVIII (1978-79), 51-62.

28 Colin, G. S., "Agdal», E.I., I (1960), 253; Marçais, G., «Bustān», E.I., 1386-87, y en L'architecture..., 404-405 y 411; Cresti, F., "Agdal, Jenan and Riyad in the African Maghreb", Enviromental Design, 1 (1986), 58-64.

29 También se atribuye una función recreativa a los lagos artificiales en los que Ibn Zaydūn, según H. Pérès, Esplendor de al-Andalus, Madrid, 1990, p. 138, señala que se bebía en los albergues de las orillas entregándose al placer de nadar o al deporte del remo. Aunque su referencia alude al embalse o lago artificial de Mālik (musannāt Mãlik) en torno a Córdoba, parece claro que puede hacerse extensible a otros lagos cuando además indica que es una moda que comienza a principios del siglo xI y que se multiplicaron en el siglo xII, sin duda como réplica a los utilizados por los grupos dirigentes. 
primer ejemplo parangonable es la almunia al-Rummāniyya, construida por un alto funcionario califal, el tesorero Durrī el Chico, quien la regaló en 973 al califa al-Hakam II. Está situada al O de Madinat al-Zahrā' y dispone de una alberca prácticamente rectangular, con unas dimensiones de 50 por $28 \mathrm{~m}$, rodeada por un andén (fig. $5 \mathrm{~b}$ ). Está contigua, aunque no se halla en eje, con la zona residencial compuesta por una estructura rectangular de tres crujías paralelas acotadas en sus extremos que dominan tres amplias terrazas escalonadas ${ }^{30}$.

Un eco algo distante de estos planteamientos rige el palacio de Galiana ${ }^{31}$, almunia construida extramuros de Toledo por los Banū DîiNūn, reyes de la taifa toledana. En este palacete de recreo jugaba un papel destacado el salón de aparato denominado de la Noria, la alberca y sus deliciosos jardines donde se aclimataron ciertas especies, atribuidos a Ibn Wāfid en colaboración, posiblemente, con Ibn Bașșāl. Su alberca es de dimensiones modestas (18,2 por $15,6 \mathrm{~m})$, hallándose en eje pero a nivel inferior respecto al pabellón $(23,75$ por $14,40 \mathrm{~m})$ de tres crujías paralelas con los extremos acotados por estancias (fig. 5c). Sobre estas crujías se levanta un segundo piso cuyas habitaciones se desarrollan sobre las estancias extremas, no conservándose entre ellas restos de construcción aunque existen indicios de que pudo haberlas. A pesar que las dimensiones actuales de la alberca no tienen parangón con los ejemplos norteafricanos, existen otros indicios que sugieren su inclusión en este grupo, tales como su esquema de crujías que remite a la Dār alMulk de Madīnat al-Zahrā' y a la almunia al-Rummāniyya o su desarrollo en vertical asociado a un estanque que haría recordar los palacios siculo-normandos de la Zisa o la Cuba.

Más explícitos son los rasgos que caracterizan la Buḥayra (diminu-

30 Esta almunia fue parcialmente excavada e identificada con al- ${ }^{\circ}$ Āmiriyya, almunia real del siglo x vinculada a Almanzor, por R. Velázquez Bosco, Medina Azzahra y Alamiriya, 1912. Fue recogida por M. Gómez Moreno, "Arte árabe español hasta los Almohades", Ars Hispaniae, III, Madrid, 1951, 166 y 171. Tras la publicación de M. Ocaña Jiménez, "Las ruinas de Alamiría, un yacimiento arqueológico erróneamente denominado", Al-Qantara, 5 (1984), 365-381, ha quedado resuelta su identificación. El texto utilizado en esta identificación pertenece a Ibn Hayyān, Anales palatinos del califa de Córdoba al-Hakam II, por 'Īsà ibn Ahmad al-Rāzī, trad. E. García Gómez, Madrid, 1967, 136-137.

31 Gómez Moreno, M., Arte mudéjar toledano, Madrid, 1916, 11-12 y 16, donde reproduce las dos fachadas antes de su restauración, no apreciándose vestigios de la alberca aunque, tal vez, exceda el enfoque de la fotografía. Delgado Valero, C., Toledo islámico..., 94-96 y 211-213; Pérez Higuera, T., Arquitecturas de Toledo, Toledo, 1991, 342-347. 
tivo de «lago»), palacete fortificado extramuros de Sevilla, iniciado en 1171 y cuyo proceso de construcción, así como la plantación de sus jardines, es descrita con gran detalle por Ibn Șāḥib al-Ṣalāt ${ }^{32}$. La gran alberca o buhayra, prácticamente cuadrada con $41,50 \mathrm{~m}$ de lado (fig. $5 \mathrm{~d}$ ), tenía su frente occidental ocupado por una crujía rectangular acotada en su extremos y rodeada completamente por un pórtico. En el eje del lado sur se elevaba un pabellón cuadrado abierto en sus cuatro frentes ${ }^{33}$.

Coetáneas a esta construcción son una serie recientes descubrimientos en la Murcia mardanī̌ś. Se trata de una alberca y una serie de estructuras imprecisas localizadas en la finca palatina del Castillejo de Monteagudo, próxima a Murcia. En torno al segundo tercio del siglo XII el monarca independiente Ibn Mardanī̌s construyó este conjunto palatino, entre cuyos restos se encuentra una gran alberca que mide 161 por $136 \mathrm{~m}^{34}$. Otra alberca de menores dimensiones, 60 por $58 \mathrm{~m}$, se halla en las proximidades del Castillejo, situándose al pie de las ruinas de la almunia fortificada conocida como el Castillo de Larache ${ }^{35}$. En ambos casos se desconoce, por el momento, si contaron con estructuras construidas en su entorno próximo mediante las cuales podrían adquirir un carácter más oficial que las hicieran dignas de algún tipo de recepción, protocolo o albergue de personas de alto rango. Por ello, sólo cabe atribuirles unas funciones utilitarias como la irrigación de la finca palatina o a lo sumo finalidades recreativas.

32 Ibn Sāhib al-Salāt, Al-mann bi-l-imāma, trad. A. Huici Miranda. Valencia, 1969, 188-191, en la nota 1 señala que Buhayra además de diminutivo de "lago» tenía en época almohade el significado de huerto o parque irrigado; Bosch Vilá, J., Sevilla Islámica, 7121248, Sevilla, 1984, 279-283.

33 Collantes de Terán, F. y Zozaya, J., "Excavaciones en el palacio almohade de la Buhayra", Noticiario Arqueológico Hispánico, I (1972), 221-260, en la p. 232 indica que las dimensiones de la alberca, tomadas desde el interior, son las siguientes: pared $\mathrm{S}$ 41,65 m, pared O 41, $50 \mathrm{~m}$, pared E $41 \mathrm{~m}$ y pared N 42,20 m; Moreno Menayo, M. T., "Los jardines y alcázares musulmanes de la Buhayra (Sevilla)", Actas del II Congreso de Arqueología Medieval Española, Madrid, 1987, vol. 3, Madrid, 1987, vol. 3, 43-51. Más recientemente, y aún inéditas, son las excavaciones de Fernando Amores, algunos de cuyos hallazgos refiere R. Manzano Martos, "Casas y palacios en la Sevilla almohade. Sus antecedentes hispánicos", Casas y palacios de al-Andalus. Siglos XII y XIII, ed. por J. Navarro Palazón, Madrid-Barcelona, 1995, p. 340.

34 Navarro Palazón, J. y Jiménez Castillo, P. «El Castillejo de Monteagudo: Qașr ibn Sa d", Casas y palacios de al-Andalus. Siglos XII y XIII, p. 95, donde también recoge otro albercón rectangular ubicado a menos de un kilómetro del Castillejo, en la pedanía de Cabezo de Torres, de 90 por $78 \mathrm{~m}$.

35 Ibidem, p. 95. 
Ya en época nazarí está documentado otro ejemplo atribuido a Yūsuf I (1333-1354), aunque su fundación parece remontarse a Sayyid Ishāâ, 1218-1219, en época almohade. Se trata de Alcázar Genil, una almunia situada en la margen izquierda del Río Genil, a menos de un kilómetro de Granada. Su gran estanque de $121,40 \mathrm{~m}$ por $28 \mathrm{~m}{ }^{36}$ guarda mayor similitud con las dimensiones de los ejemplos norteafricanos, alzándose en uno de sus lados cortos un pabellón, recientemente restaurado.

Dentro del ámbito siciliano, el primer exponente documentado, aunque con una cronología imprecisa, es la Favara (fawwāra, chorro de agua) o castillo del Mar Dulce. Amari ${ }^{37}$ atribuye su construcción al emir Ŷa far ibn Yūsuf (998-1019), aunque hay indicios de que este lugar fue habitado con anterioridad y posterioridad a tal momento. Su inmenso estanque irregular cuenta con unas dimensiones tan espectaculares que permitían la existencia de una isla en su interior (fig. 6a y lám. 2). En él introducía tres de sus lados un edificio organizado en torno a un patio porticado cuya disposición, de ser más regular, recordaría un palacio omeya del desierto ${ }^{38}$.

36 Gómez Moreno, M., Guía de Granada, Granada, 1892, reimp. 1982, 236, indica que en uno de sus extremos se conservan los «cimientos y la parte subterránea de una extensa nave de edificio, que probablemente mediría $34 \mathrm{~m}$ por 5 , con su correspondiente pórtico, desde el cual gozarían de una hermosa vista..... También alude a ella J. Dickie, «Notas sobre jardinería árabe en la España musulmana», Miscelánea de Estudios Árabes y Hebraicos, XIV-XV (1965-66), p. 82, y en "Gardens in Muslim Spain", Environmental Design, 1 (1986), p. 82. Una reconstrucción hipotética de su pabellón en A. Orihuela, "Granada, capital del reino nazari", La arquitectura del Islam Occidental, coord. por R. López Guzmán, Madrid-Barcelona, 1995, 199 y 202.

37 Amari, M., Biblioteca arabo-sicula, Turín-Roma, 1880, reimp. 1982, I, 23, 155, y II, 47, 139, 439-441; U. Rizzitano, «Kalbides», E.I., IV (1987), 518.

38 Estos datos fueron contrastados in situ en una visita realizada en compañía de Silvana Braida que lleva años trabajando sobre este edificio, y a quien agradezco su amabilidad e información. Igualmente agradezco las explicaciones de Amadeo Tulio sobre los trabajos arqueológicos allí efectuados. Cf. Braida, S., «Il Castello di Favara. Studi di restauro", Incontri e Iniziative, Memorie del Centro di Cultura di Cefalú, núm. V, 2, 1988 (1992), 65-89. Marçais, G., L'architecture..., p. 120; Di Stefano, G., Monumenti della Sicilia Normanna, 2. éd. por W. Krönig, Palermo, 1979, 90-91 y 101-112; Gabrieli, F., Pagine Arabo-Siciliane, 1986, p. 28; Bresc, H., "Genèse du Jardin Meridional. Sicile et Italie du Sur XII-XIII siècles", Jardins et Vergers en Europe Occidentale (VIII-XVIII siècle), Auch, 1989. También merece la pena recordar la poesía del secretario de Roger II, 'Abd alRaḥmān al-Itrabanišĩ dedicada a la Favara y recogida por A. F. Von Schack, Poesía y arte de los árabes en España y Sicilia, Madrid, 1988, 1988, 244-245: «Palacio de los palacios, / cuál resplandeces, Favara, / mansión de deleites llena, / a orilla de entrambas aguas! / Nueve arroyos, que relucen / en tus prados de esmeralda, / riegan los bellos jardines / con onda fecunda y clara. / Dos surtidores se empinan / y en curva buscan la taza, des- 
Tras la conquista normanda se construyeron algunos palacios siguiente este esquema tipológico. Así sucede con los edificios vinculados al reinado de Roger II (1130-1154) en los que el gran estanque estaría asociado a estructuras en que prima la horizontalidad, tales como la readaptación del palacio del Mar Dulce o Favara y un pabellón en el Parque Nuevo en Altofonte ${ }^{39}$. Otros, relacionados con los reinados de los Guillermos, desarrollaron una nueva tipología en vertical como sucede con el edificio de la Cuba, inmerso en su correspondiente gran estanque, obra de Guillermo II en $1180^{40}$.

Menor atención han recibido los jardines islámicos egipcios y tal vez por ello sólo se dispone de una referencia documental que alude a la existencia de un ejemplo que se adapta a este esquema y que pertence a época fatimí. Está recogido por al-Maqrīzī, indicando que contaba con un gran estanque en medio del cual se levantaba un pabellón octogonal de mármol entre naranjos. Un puente realizado en cobre cruzaba el estanque sobre el que flotaban barcas ${ }^{41}$.

menuzándose en perlas / que el iris fúlgido esmalta. / En tus lagos amor bebe / elixir de bienandanza / junto a tu raudal su tienda / tiene el placer desplegada; /Quinta mejor que tu quinta / en el mundo no se halla; / nada más lindo que el lago / do se miran las dos palmas. / Sobre él los árboles doblan / las verdes y airosas ramas, / como para ver los peces / que por sus cristales nadan, / y que de carmín y oro / el líquido seno cuajan. / Mientras que encima las aves / gorjean en la enramada. / ¿Oh cuán hermosa isla, / donde brillan las naranjas, / entre el verdor de las hojas, / como relucientes llamas / y los pálidos limones / como en noche solitaria / un amador melancólico / que está lejos de su amada! / Las dos palmas que crecieron / sobre la misma muralla, / allí parecen amantes / que temerosos se amparan, / O más bien, que con orgullo / su fina pasión proclaman, / y los celos desafían, / y burlan las amenazas. / Nobles palmas de Palermo, que la lluvia en abundancia / os bañe; creced frondosas / mientras duerme la desgracia / y que florezcan en tanto / árboles, yerbas y plantas, / tálamo dando mullido / al amor y sombra opaca."

39 Braida, S., "Il palazzo ruggeriano di Altofonte», Palladio, 1973, 185-197; Di Stefano, G., op. cit., pp. 97-99; Noto, V., "Les palais et les jardins siciliens des rois normands", Trésors romans d'Italie du Sud et de Sicile, Milán, 1995, 104-107. En todos ellos se aportan noticias sobre el palacio del parque en Altofonte y su relación con la Favara, pero no aluden al pabellón y su gran estanque, sobre el cual está realizando trabajos de restauración en estos momentos Vittorio Noto, a quien agradezco la visita al lugar y la información.

40 Marçais, G., L'architecture..., p. 121; Bellafiore, G., La Zisa di Palermo, Palermo, 1978; Di Stefano, G., op. cit., 108-110; Caronia, G. y Noto, V., La Cuba di Palermo, Palermo, 1988; Staacke, U., Un palazzo normanno a Palermo. La Zisa. La cultura musulmana negli edifici dei Re, Palermo, 1991, 162-167; Caselli, P., «La Conca d'oro e il giardino della Zisa a Palermo", Il giardino islamico. Architectura, natura, paesaggio, comp. por A Petruccioli, Milán, 1994, 185-200.

41 Behrens-Abouseif, D., "Gardens in islamic Egypt", Der Islam 69/2 (1992), 305, tomado de al-Maqrīīi, Kitāa al-mawā iz wa-l-i tibār bi-dikr al-jittat wa-l-ātāâr. Bulaq, 1306/1888-89, I, 487 
De la presencia en todos estos ámbitos geográficos de lugares con grandes estanques asociados a pabellones no se pueden extraer argumentos concluyentes debido a que, en unos casos, sólo se cuenta con referencias documentales y, en otros, se carece de los datos relativos a las dimensiones de sus estanques, a la existencia de pabellones, a la localización y organización de éstos respecto al estanque, así como a la organización y dimensión del espacio en el que éstos se ubican (fig. 4). A pesar de ello parece atisbarse que desde un primer momento son lugares concebidos con funciones de recreo, pero que al ser patrocinados por los grupos más relevantes de la sociedad islámica podían servir de escenario idóneo para algún uso protocolario o para agasajar a ciertos invitados. De esta forma, tanto el estanque como la amplia superficie irrigada por él se convertirían en un lugar de solaz en el que tendrían cabida desde el esparcimiento vinculado al agua como las fiestas acúaticas simulando paseos acompañados por música y bebida, a la experimentación o el cultivo de determinadas especies e incluso contar con la presencia de animales.

De ser esta explicación plausible llevaría a cuestionar el origen de estas organizaciones palatinas entendidas como lugares en que se compaginaban funciones de recreo con actividades agropecuarias. En este sentido podrían aducirse varios posibles orígenes que participan de elementos comunes y que se relacionan con las posibles funciones atribuidas a los palacios del desierto omeya. El primero estaría en relación con bādiya que ha sido caracterizado como un lugar donde los príncipes omeyas pasaban varias semanas al año fortaleciendo los vínculos con los grupos tribales, disfrutando del aire libre y practicando la ca$\mathrm{za}^{42}$. La existencia de agua tanto para cultivar como para beber podía convertirse en un aliciente para atraer animales salvajes y practicar la caza ${ }^{43}$. No obstante, no hay que perder de vista que este término procede de badāwa entendido como terreno no urbano, campo fértil, despejado, sin edificación, aplicado a la campiña siria ${ }^{44}$. Otro posible ori-

42 Teoría defendida por H. Lammens, "La Bâdia et la Hîra sous les Omaiyades», Mélanges de la Faculté Orientale, Beyrouth 4 (1910), 91-112. Ha sido contestada por J. Sauvaget, "Chateaux umayyades de Syrie. Contribution a l'étude de la colonisation arabe aux $\mathrm{I}^{\text {er }}$ et $\mathrm{II}^{\mathrm{e}}$ siècles de l'Hégire», extrait de la Revue de Études Islamiques, 1967. París, 1968, 5-13, y por H. Gaube, Ein arabischer Palast in Südsyrien. Hirbet el Baida, Beirut, $1974,119-127$.

43 Creswell, K. A. C., A Short Account of Early Muslim Architecture, rev. y sup. por J. W. Allan, El Cairo, 1989, p. 93.

44 Según recoge F. Corriente, Dictionary of andalusi arabic (en curso de publicación) 
gen se halla en el término hậit que alude a zonas cultivadas o a jardines en los alrededores de la ciudad dotados de recinto amurallado y que podían haber sido utilizados principalmente para cultivar o para animales de labranza ${ }^{45}$, pudiendo identificarse con un huerto o huerta ${ }^{46}$. Finalmente, otra posible explicación se halla en el término hayr (corrupción de hă’ir, plural hawä’ir) cuyo significado es el de cisterna o depósito de agua, recinto o jardín, asimilable al concepto de parque ${ }^{47}$. De modo que el hayr sería equivalente al paradeisos o pairidaeza persa, considerado como un recinto amurallado, jardín cerrado, parque de caza o jardín de placer ${ }^{48}$. Aunque sólo el último de los términos alude

45 Sauvaget, J., "Châteaux...", 47-48, quien lo recoge por vez primera señalando que su sentido original es el de protección o muro y secundariamente jardín rodeado por un muro. Recoge ejemplos en los que en este recinto se cultivaban olivos o pepinos y sandías o servía para pastar caballos; Grabar, O. y otros, City in the Desert. Qasr al-Hayr East, Cambridge-Massachusetts, Harvard University Press, 1978, p. 104.

46 Corriente, F., Dictionary of andalusi arabic

47 Acepción que me comunicó verbalmente F. Corriente y que es recogida en su Dictionary of andalusi arabic.

48 Sobre el concepto de hayr como paradeisos o pairidaeza, cf. Sourdel-Thomine, J., "Hā’ir», E.I., III (1971), p. 73; Pechére, R., "Etude sur les jardins iraniens", Les jardins de l'Islam. Islamic gardens. ICOMOS, Granada, 29 octubre al 4 noviembre de 1973. Granada, 1976, 19-64; Gentelle, P., «Un paradis hellénistique en Jordanie: étude de géo-archéologie", Hérodote, 20 (1. ${ }^{\text {er }}$ trimestre 1981), 70-100.

La controversia que rodea el término hayr puede seguirse a través de las distintas propuestas que se han realizado sobre el recinto de Qașr al-Hayr al-Šarqì. A su consideración como lago artificial [Gabriel, Syria, 8 (1927), p. 2340] se opuso la de paradeisos o jardín amurallado para defenderlo del pillaje beduino (Seyrig, H., "Les jardins de Kasr el-Heir", Syria 12 (1931), 316-318; Syria, 15, 24-32). Esta polémica fue zanjada por K. A. C. Creswell, Compendio de arquitectura paleoislámica, Sevilla, 1979, 154-156, opinando que el recinto era un jardín para animales, una reserva de caza, cuyos altos muros impedían que éstos escapasen. Sin embargo, más recientemente, O. Grabar, City in the Desert, 103-104, ha sugerido la posibilidad de que este recinto fuese un lugar destinado principalmente para pastar animales con la posibilidad de que contase con áreas destinadas al cultivo.

Sobre sus acepciones en al-Andalus, Dickie, J., «The Hispano-arab garden: notes towards a typology", The Legacy of Muslim Spain, Leiden-Nueva York, p. 1018, la recoge con el significado de cisterna o estanque aplicada a la descripción de la Alhambra, siguiendo la descripción de Ibn al-Jațib (1313-1375), en Al-Lamha l-badriyya fí l-dawla l'Nașriyya, Cairo, $1347 / 1927$, p. 14. En cambio H. Pérès, Esplendor..., p. 134 y nota 52, indica que los términos häìr y hayr parecen sinónimos, aunque el primero tiene un uso más antiguo, interpretándolos como pabellón y quiosco. En este caso, parte de la descripción del Hayr al-Zaŷyâalī, en las proximidades de Córdoba, realizada por al-Fath ibn Jãqān en Qalä̉id., p. 135 (reprod. en Anal, I, 420), y Yāqūt, Mu ŷam al-Buldān, II, 374. También recoge el hä̉ir o parque con animales con casa de fieras y pajareras con el que 'Abd al-Raḥmān III completó Madīnat al-Zahrā' sobre cuya fuente H. Pérès, Esplendor, p. 247, y nota 39, remite a Ibn Jaldūn, Kitāb al-'Ibar, IV, 144 (reprod. en Analectes, I, 380 ). Este tema puede completarse en el mismo autor, $248-49$, n. 43 , y p. 130 , n. 36. 
explícitamente a la existencia de agua, en todos los casos está implícita o atestiguada de forma textual o arqueológica la presencia del agua. Del mismo modo que es habitual la presencia de animales, discutiéndose si éstos son domésticos o salvajes y por ende, si era un terreno de labranza o un coto de caza. Otra dificultad añadida viene dada por el tamaño del recinto y su dotación de un claro sistema interno de irrigación, dado que la mayoría de los lugares cuentan con presas, cisternas y aljibes de distintos tamaños. Y finalmente, un punto más estrechamente vinculado con los espacios aquí analizados, la relación directa o indirecta de estos recintos con estructuras construidas.

El panorama brevemente planteado conduce a que los conjuntos arqueológicos descubiertos no mantienen una exacta relación con ninguno de los tres términos - bādiya, hā ịt, hayr- aunque también pudiera considerarse un tanto artificial la pretensión de buscar una relación estricta de cada uno de ellos con una configuración genérica ${ }^{49}$. Más factible podría ser la idea de que estos términos participan de ciertas características comunes, por lo que, mientras no se disponga de mayor información, la atribución de un término no es determinante para establecer su estructura espacial.

Así pues, el estado de discusión que rodea la aplicación de cada uno de estos términos hace que, sin perder de vista su importancia para determinar la clara función de estos espacios, parezca indicado centrar el análisis en la presencia de estanques y de las construcciones vinculadas a ellos por ser el rasgo que más singulariza los conjuntos aquí recogidos.

Dentro del ámbito próximo-oriental, y concretamente en época omeya, parecen vislumbrarse estos elementos en algunos de los palacios del desierto. Tal es el caso de Qașr Burqu', el cual cuenta con una gran alberca de 100 por $150 \mathrm{~m}$ situada al NO del recinto y con una presa que formaba un lago artificial que llegaba hasta los cimientos SO del

\footnotetext{
Más recientemente J. Dickie, "Gardens in Muslim Spain", Environmental Design, 1 (1986), p. 79, recoge todas las interpretaciones anteriores y asume la acepción de hayr como pabellón, matizando que también llegaba a identificarse con el recinto en el que éste se levanta. En ninguno de los casos se interpreta el "qasr al-hä in descrito como una de las salas de aparato de los alcázares califales de Córdoba recogido por H. Pérès, Esplendor..., p. 129, n. 31, tomado de Ibn Baškuwāl en Anal., I, 302-3, y por E. Lévi-Provençal, L'Espagne musulmane au Xéme siècle, París, 1932, 222-224.

${ }_{49}$ Los tres términos pueden considerarse sinónimos desde un punto vista genérico, aunque no lo son semánticamente.
} 
Qașr ${ }^{50}$. Similar relación de estructuras tendría el palacio de Minŷa emplazado a $200 \mathrm{~m}$ de la ribera NE del lago Tiberiades ${ }^{51}$. En al-Muwaqqar existía al SE, al pie de una colina, una alberca de 34 por $31,50 \mathrm{~m}$ y a escasos metros un edificio de tres habitaciones cubiertas con bóvedas que recuerdan un plan basilical ${ }^{52}$. En Qaṣr al-Ḥayr al Garbī una presa cortaba el lecho de un antiguo $w \bar{a} d \bar{l}$, cuyo muro semicircular iba torreada al exterior, mientras que en su cara interna tenía tres torres de las cuales la central parecía haber estado rematada por un pequeño pabellón. Las otras dos torres estaban decoradas con relieves de estuco que incluían escenas de caza ${ }^{53}$. En Quṣayr al-Hallābāt han sido descubiertas fuera del castillo, al $\mathrm{O}$ y SO, cinco cisternas y una profunda alberca, al $\mathrm{O}$ de ella existen restos de un edificio arruinado ${ }^{54}$. Más confusas son las características de las estructuras del baño de Jirbat al-Mafŷar (fig. $3 c$ ) tanto por la piscina de 19,50 por $3,40 \mathrm{~m}$ ubicada en la parte sur del frigidarium como por el sistema de aducción del agua compuesto por un acueducto, una alberca cuya agua caía desde $24,5 \mathrm{~m}$ moviendo molinos de agua, para pasar a otra alberca cuadrada y desde allí al baño 55 . De todos estos castillos, tal vez, las circunstancias que rodean el baño de Jirbat al-Mafŷar presentan mayor similitud con los primeros ejemplos norteafricanos, puesto que, con independencia de su función como lugar de recepción, se han puesto en relación con actividades acúaticas y frívolas en consonancia con el carácter de al-Walīd. De esta forma tanto la espaciosa piscina, la cascada, las pequeñas piscinas, la inundación del propio pavimento del frigidarium, así como las exedras para músicos y recitadores configuran un espacio lúdico donde agua y arquitectura son los elementos fundamentales. Al mismo tiempo, la utilización previa del agua para mover molinos y, tal vez, para otros fines completan la faceta utilitaria de estas instalaciones.

50 Gaube, H., "An Examination of the Ruins of Qasr Burqu'", Annual of the Department of Antiquities of Jordan, XIX (1974), pp. 93, 98 y 99.

51 Grabar, O., et al., "Sondages à Khirbet el Minyeh", Israel Exploration Journal, 10 (1960), pp. 226-243; Creswell, K. A. C., A Short Account of Early Muslim Architecture, rev. y sup. por J. W. Allan, El Cairo, 1989, p. 93.

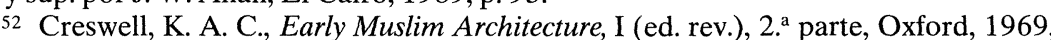
p. 495. Waheeb, M., "The Second Season of Excavations at al-Muwaqqar", Annual of the Departament of Antiquities of Jordan, XXXVII (1993), pp. 5-23.

53 Creswell K. A. C., y Allan, J. W., A short account..., p. 136; Sauvaget, J., "Châteaux...", p. 25, indica que la capacidad de esta presa o reserva de agua era de $140.000 \mathrm{~m}^{2}$, de ella partía una canalización que alimentaba a $16,500 \mathrm{~km}$ una alberca de $13.000 \mathrm{~m}^{2}$.

54 Creswell, K. A. C., y Allan, J. W., A short account..., pp. 164-165.

55 Ibidem, 180 y 200. 
A pesar de que estas estructuras parecen sugerir un posible modelo que no se logra plenamente definir debido, en parte, a una falta de documentación, es evidente que en época 'abbāsí está plenamente conformado. Éste aparece en el palacio de Ŷawsaq al-Jāqānī en Sāmarrā' ${ }^{56}$ construido por el califa al-Mu'tașim (833-842). Su eje principal se inicia frente a un gran estanque de 100 por $127 \mathrm{~m}$ flanqueado por jardines a ambos lados (fig. 7). Entre el estanque y la ribera del río Tigris un pequeño pabellón dominaba el estanque, el río y el paisaje. En sentido opuesto una gran escalera de $60 \mathrm{~m}$ de anchura conectada el estanque con la $b \bar{a} b a l^{-} \bar{A} m m a$ cuyos tres iwanes eran utilizados tanto como entrada al palacio como sala de audiencias públicas del califa ${ }^{57}$. De esta forma, queda configurado un espacio en el que se aúnan funciones protocolarias y de placer.

A partir de estos ejemplos y de su hipotética relación con las estructuras norteafricanas se pueden establecer dos posibles orígenes. Uno, vinculado al mundo omeya sobre bases tardo-antiguas, hecho que está corroborado por la existencia de vestigios de asentamientos romanos y/o bizantinos en un buen número de castillos del desierto ${ }^{58}$. Esta situación es comparable a una gran parte de los complejos hidráulicos norteafricanos a los que se ha atribuido una filiación romana, si bien está en revisión la concreta adscripción de cada uno de ellos ${ }^{59}$. El otro estaría en relación con la época 'abbāsí sobre concepciones sasánidas entre las que cabe incluir la utilización de un gran estanque ante la en-

56 Su excavación fue realizada por Herzfeld en las primeras décadas del siglo xx; su testimonio aparece recogido en Creswell, K. A. C., Early Muslim Architecture, II. New York, 1979, pp. 232-243. Un esquema parecido en el que el río actuaría con la misma función que un estanque puede plantearse en el palacio de Balkuwārā, ibidem, pp. 265266 , dado que en la parte posterior había «un jardín rodeado de muros con pilastras que acababa sobre la propia orilla (del Tigris) en pabellones ricamente decorados».

57 Ibidem, p. 234; Hoag, J. D., Arquitectura islámica, Madrid, 1976, p. 48, señala que en el iwan central se situaba la sidilla o trono con baldaquino.

58 Creswell, K. A. C., y Allan, J. W., A short account..., pp. 93 y 164; J. Sauvaget, "Châteaux...", recoge los antecedentes preislámicos de un gran número de palacios entre los que se encuentran los aquí reseñados, cf. pp. 26, 32 y 35. Grabar, O. et al., «Sondages a Khirbet el Minyeh...", p. 240.

59 Gauckler, P., Enquête sur les installations hydrauliques romaines en Tunisie, Túnez, 1897-1902, 2 vols., junto a grandes aljibes cubiertos y al aire libre recoge en el tomo I, 47-49, ejemplos de estanques rectangulares a los que atribuye usos lúdicos, como piscina. No obstante, concluye precisando que la zona central de Túnez no estuvo cubierta de cultivos de irrigación, utilizándose estas obras hidráulicas para usos personales, como bebida de hombres y animales de labranza. Grabar, O., City in the Desert., p. 104, pone en relación los canales de al-Šarqī con los romanos de Túnez. 
trada monumental, así como la localización del palacio en terrazas o desniveles que sirviesen para dominar el jardín circundante ${ }^{60}$.

Así pues, parece evidente que el modelo 'abbāsí, con independencia de haber podido contar con posibles tanteos en época omeya, se presenta como el precedente de los ejemplos norteafricanos. Y tal vez por ello, en un primer momento se haya asociado más directamente con lugares de recepción dentro de ciudades palatinas para pasar a desligarse, en parte, y adquirir su propia autonomía como huertas o parques de recreo. De esta forma, al no quedar constreñido a la ciudad o a un recinto palatino, podían alcanzar unas mayores dimensiones que facilitaban una diversidad de funciones entre las cuales se hallasen, posiblemente, las protocolarias, pero, sobre todo, las recreativas.

Una vez puesta de relieve la existencia de una serie de manifiestaciones artísticas que vinculan determinados ámbitos del Mediterráneo y cuyo origen se relaciona con el mundo tardo-antiguo, bien helenístico, bien romano-bizantino o sasánida, se suscitan numerosos interrogantes.

En primer lugar habría que establecer el papel de Túnez. Está aún por determinar si Túnez funcionó como correa de transmisión entre el Oriente y el Occidente islámico o si puede atribuírsele la capacidad de foco creador. No obstante, tal vez quepan ambas posibilidades y el repertorio utilizado tenía una procedencia oriental, si bien su concreción formal se realizó en Ifrīqiya ${ }^{61}$

En segundo lugar y respecto a los focos receptores habría que establecer si concurren algunas circunstancias específicas que determina-

60 Pinder-Wilson, R., "The Persian Garden: Bägh and Chahar Bägh», en Islamic Garden, ed. E. MacDougall y R. Ettinghausen. Washington, 1976, pp. 72-75, lo pone en relación por su similar organización con los palacios persas 'Imārat-i Jusrau en Qașr-i Sirin y Haws Kuri, ambos construidos por Cosroes II Parviz (591-628 a. C.). También en Ruggles, F., "The mirador in abbasid and hispano-umayyad garden typology", Muqarnas 7 (1990), p. 75 y n. 8 .

61 Los grandes especialistas en el arte norteafricano ven en el arte aglabí una relación con Oriente, si bien sus divergencias provienen de su lugar de procedencia. Es decir, si son sirio-omeyas o mesopotámico-abbāsies. La influencia mesopotámica sobre la arquitectura aglabí del foco de Qayrawān es defendida por G. Marçais, L'architecture..., p. 61, y por A. Lézine, Architecture d'Ifriqiya. Recherches sur les monuments aghlabides, París, 1966, pp. 87-88. Sin embargo, el último cuarto de siglo en que esta dinastía estuvo en el poder se observa un retorno a la influencia de la Siria omeya según A. Lézine, "Sur deux châteaux musulmans...", p. 94. L. Golvin, "Le mihrab de Kairouan», Kunst des Orients, V, 1969, 1-38, ha tendido a minimizar la influencia mesopotámica en Qayrawān, pensando que lo que parecía mesopotámico provenía de Siria, donde también las influencias sasánidas se habían dejado sentir durante mucho tiempo. 
ron la aparición de una misma cultura material. Son conocidas las relaciones marítimas y terrestres que existieron entre estos lugares, aunque no hayan sido suficientemente estudiadas desde el punto de vista artístico ${ }^{62}$. Otro posible nexo común a tener en cuenta es la presencia de kalbíes ${ }^{3}$ en todos los focos, si bien no existe ningún argumento para demostrar que su simple presencia se tradujera en un vehículo de relación. No obstante, no hay que perder de vista que en las distintas zonas formaban parte de los grupos dominantes y/o gobernantes por lo que no es de extrañar que utilizaran un lenguaje artístico común como signo de poder. Evidentemente no se trata de defender una identidad étnicocultural, puesto que, aunque este grupo tribal era de origen yemení y por tanto acostumbrados a la utilización y adecuación de complejos sistemas hidráulicos adaptados a su topografía, rápidamente adquirieron los usos y costumbres de los lugares donde se asentaron. Así pues, por el momento, no existe ninguna razón concluyente que vincule dichos focos. Del mismo modo que tampoco es posible precisar si la relación observada entre ellos pudo obedecer a alguna de las dos hipotéticas vías de transmisión; es decir, una directa desde Túnez con cada uno de los focos u otra indirecta, mediante la relación de los propios focos entre sí.

En cualquier caso, los interrogantes expuestos no empañan la relación que existe entre determinados puntos del Mediterráneo fundamentalmente entre los siglos Ix y XII y que queda refrendada a través de una serie de manifestaciones artísticas.

\footnotetext{
62 De todos son conocidas las relaciones comerciales entre estos lugares como recogía Ch. Courtois, "Remarques sur le commerce maritime en Afrique au $\mathrm{XI}^{\mathrm{e}}$ siècle", Mélanges d'Histoire et Archéologie de l'Occident Musulman, vol. II, Argel, 1957, pp. 51-59. Más recientemente y con unos planteamientos más amplios, cf. Lirola Delgado, J., El poder naval de al-Andalus en la época del Califato Omeya, Granada, 1993.

${ }^{63}$ Los Kalbíes, familia descendiente de la tribu Kalb b. Wabara, de origen yemení, eran conocidos en las fuentes árabes del Magreb como los Banū Abī 1-Husayn Con los Omeyas desempeñaron cargos de gobernadores y altos funcionarios de la administración en Ifrīqiya. Su poder comenzó a declinar con los aglabíes, si bien con los fatimíes alcanzaron las cotas de su máximo prestigio político y religioso que les llevó a ser enviados por los imames de El Cairo como gobernadores de Sicilia. Cf. Rizzitano, U., «Kalbides", E.I., t. IV (1978), pp. 517-519, y Amari, M., op. cit. La participación de los Kalbíes en la conquista de al-Andalus y su apoyo para la venida del pretendiente Omeya, futuro 'Abd al-Raḥmān I, en Dixon, A. A., "Kalb b. Wabara», E.I., t. IV (1978), pp. 515-516.
} 


\section{RESUMEN}

Entre los siglos IX y XII son varias las manifestaciones artísticas que vinculan a Túnez con al-Andalus, Egipto y Sicilia. Se trata, más concretamente, de los cipos funerarios, de las mezquitas de nueve tramos y de los conjuntos de carácter áulico caracterizados por contar con un gran estanque. La documentación de estos modelos tipológicos, así como la aproximación a sus posibles orígenes y funciones llevan a plantear el papel de Ifrīqiya como foco creador o de concreción formal de los modelos, actuando los focos restantes como receptores.

\section{ABSTRACT}

Between the ninth and twelfth centuries various types of artistic activity linked Tunisia with al-Andalus, Egypt and Sicily. More specifically, this artistic exchange consisted of funeral columns, mosques constructed in nine compartments and court gardens characterised by one large pool. This article studies the documentation available and assesses the possible sources and functions of these typological models. The role of Ifriqiya is then posited as the origin of the models or either as the place where these models were formally established to then serve as influential for al-Andalus, Egypt and Sicily. 

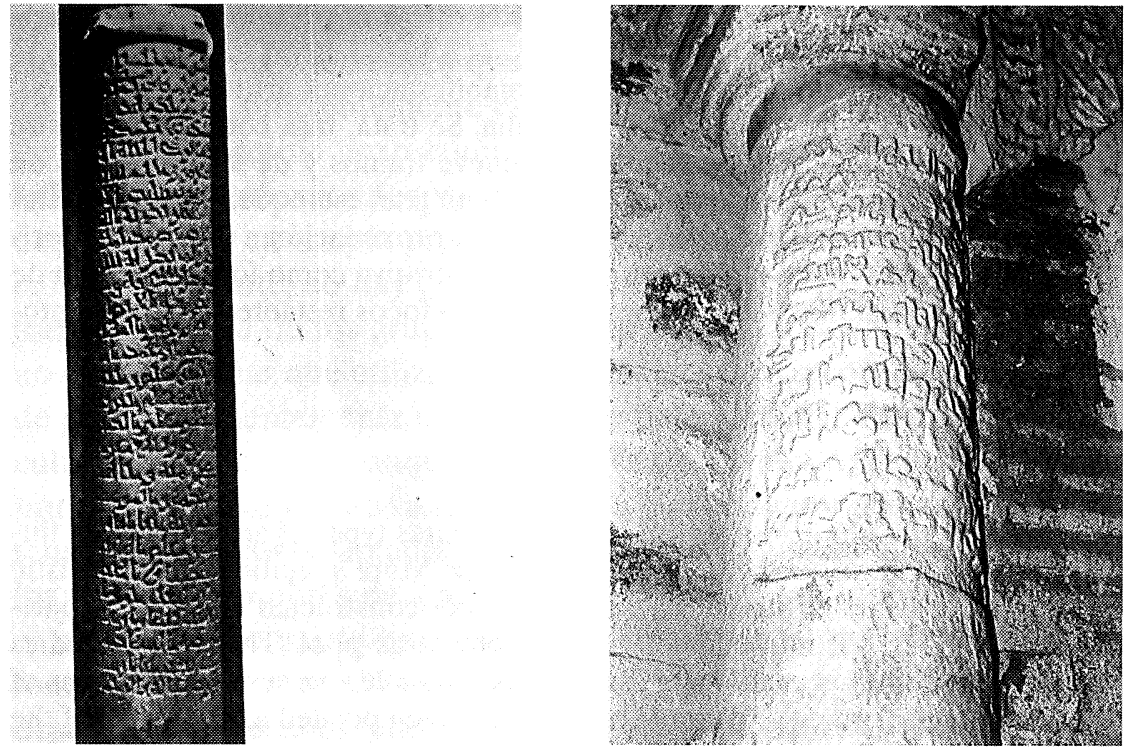

$1 \mathrm{a}$

$1 b$

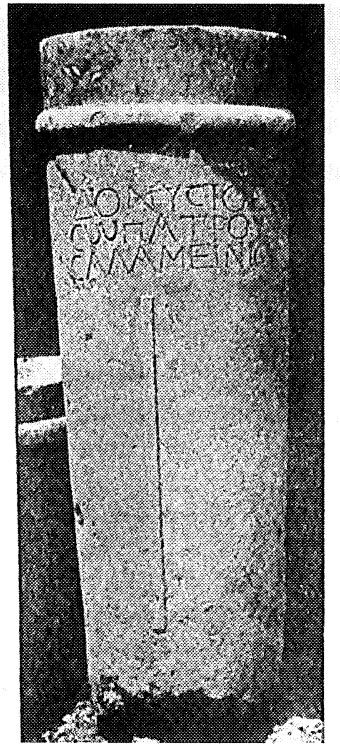

Lámina 1a. Columna funeraria de Qayrawān, siglo x, núm. 6, de Zbiss. 1b. Cipo funerario toledano, 1001. Forma parte de un enterramiento en lucillo de la iglesia de San Andrés de Toledo

1c. Columna sepulcral de Atenas, núm. 1800 de Conze. 


\begin{tabular}{|c|c|c|}
\hline \multirow{4}{*}{$\begin{array}{l}\text { TUNEZ } \\
\text { 862-FIN XIV }\end{array}$} & QAYRAWĀN & $862-1 / 2 \mathrm{XI}$ \\
\hline & SUSA Y SFAX & XI y XII \\
\hline & MONASTIR & XI-XIV \\
\hline & GORJANI & $\begin{array}{l}\text { fin XIII- } \\
\text { fin XIV }\end{array}$ \\
\hline AL-ANDALUS & TOLEDO & XI (1001) \\
\hline \multirow[t]{2}{*}{ EGIPTO } & ALEJANDRIA & XI (1015)- \\
\hline & DELTA & $1 / 2 \mathrm{XIV}$ \\
\hline \multirow[t]{2}{*}{ ITALIA } & NÁPOLES & XI (1054)y \\
\hline & SICILIA & XII \\
\hline
\end{tabular}

Fig. 1a. Distribución de los cipos funerarios

GOLOMBEK

1. SUSA, BŪ FAṬĀṬA

2. QAYRAWĀN, TRES PUERTAS

3. MOSUL, NABĪ YIIRȲIS

4. CAIRO, TABĀTABĀ

5. TOLEDO, BĀB AL-MARDÜM

6. HAZĀRA, DIGGARĀN

7. ASWĀN, 77 GOBERNADORES

8. TOLEDO, TORNERIAS

BALJ $1 .^{\mathrm{a}} \mathrm{m} . \mathrm{IX}=\mathrm{EL}$ ORIGEN

\begin{tabular}{|c|c|c|}
\hline \multirow[b]{2}{*}{$838-841$} & \multicolumn{2}{|l|}{ KING } \\
\hline & BŪ FAṬĀṬA & $838-841$ \\
\hline 866 & M. BALJ & IX-XI \\
\hline IX? & CHAHAR SUTUM & $\mathrm{X}$ \\
\hline 950 & DIGGARĀN & $\mathrm{X}-\mathrm{XI}$ \\
\hline 999 & BĀB AL-MARDŪM & 999 \\
\hline 1000 & TORNERIAS & 1159 \\
\hline 1000 & TABĀTABĀ & $\mathrm{XI}$ \\
\hline 1159 & 77 GOBERNAD. & $\mathrm{XI}$ \\
\hline & M. FIYALA & XI-XII \\
\hline & NABİ ŶIRYYIS & XII-XIII \\
\hline
\end{tabular}

Fig. 1b. Cronología de las mezquitas de nueve tramos 

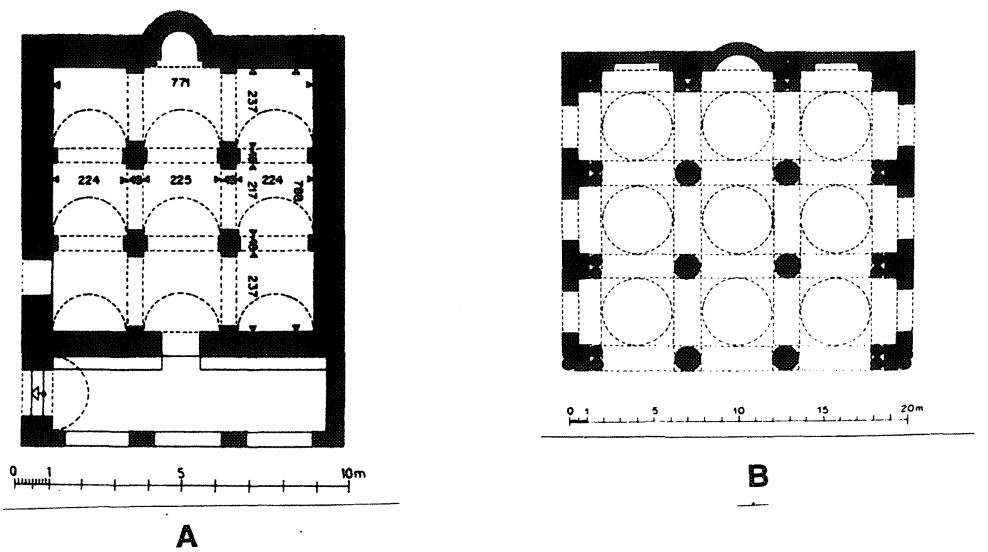

B
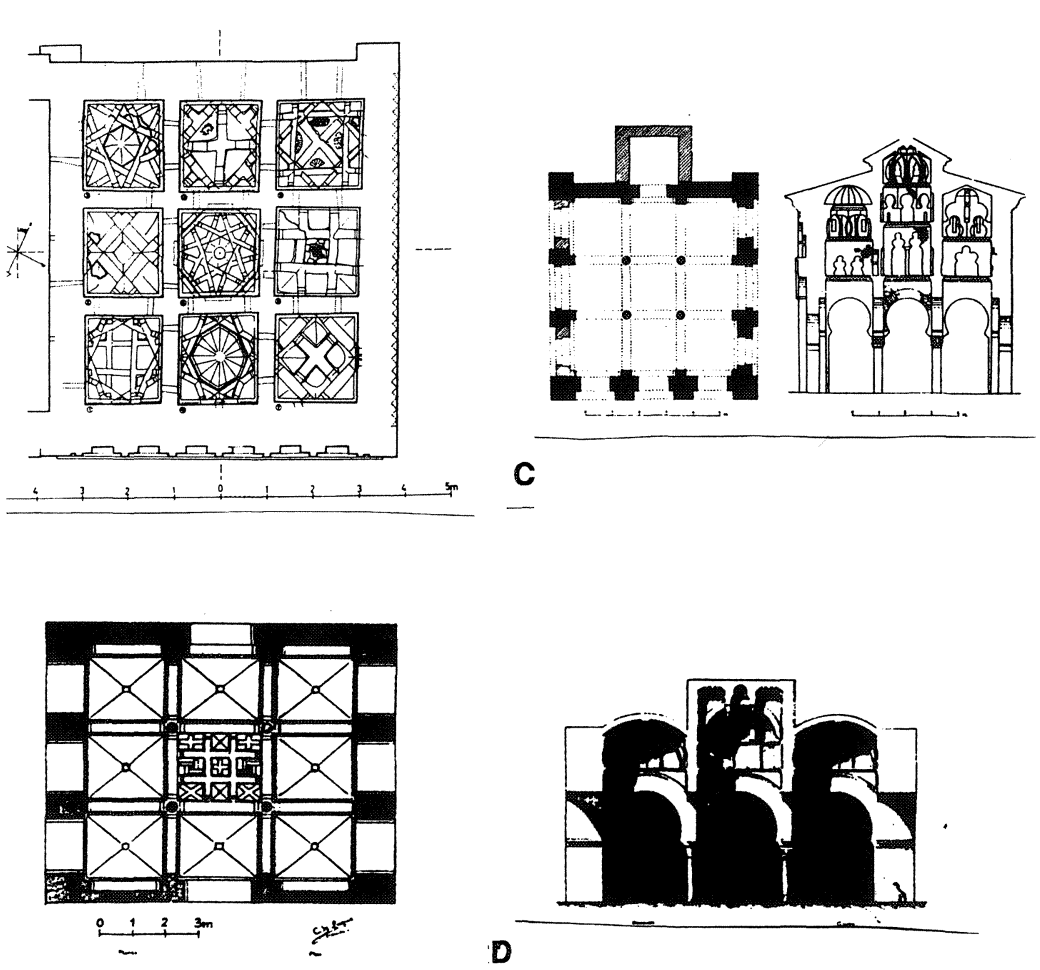

Figura 2a. Mezquita de Bū Fațāta, Túnez (Creswell y Ewert). 2b. Mezquita de Balj, Afganistán (Golombek).

2c. Mezquita de Bab al-Mardūm, Toledo (Ewert y Gómez Moreno). 2d. Mezquita de Tornerías, Toledo (Amador de los Ríos). 

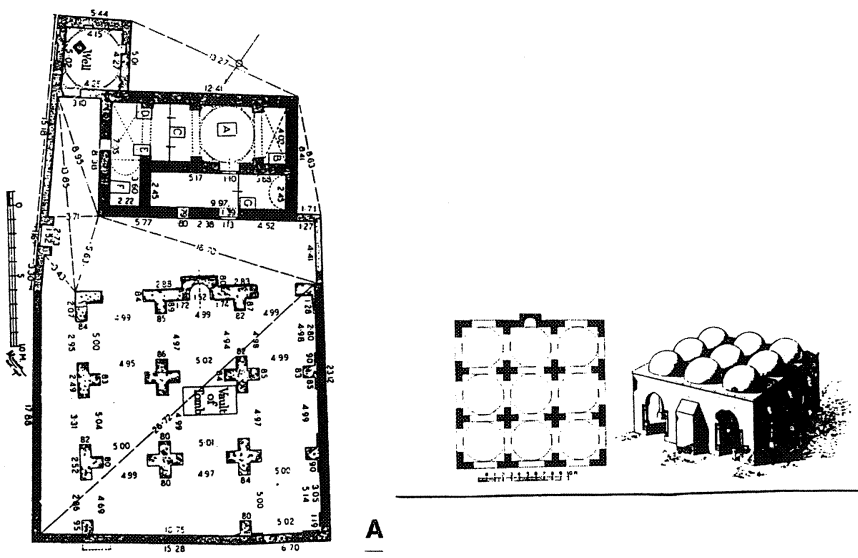

A
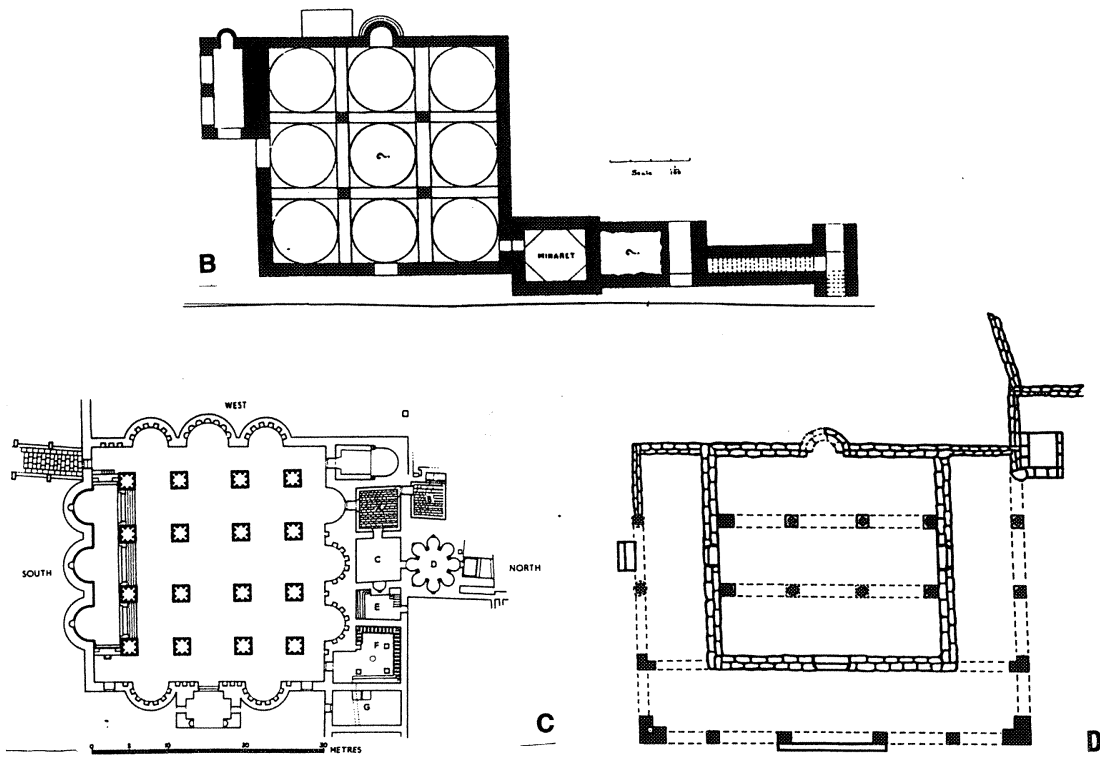

Figura 3a. Šarīf Tabātabā, El Cairo (F. Shafíi).

3b. Tumba de los 77 Gobernadores (Sab'a wa-Sab'in Wālì), Aswān, Egipto (Somers Clarke-Creswell).

3c. Frigidarium-Sala de Audiencias de Jirbat al-Mafŷar, Palestina (Hamilton) 3d. Mezquita de Qusayr al-Hallabat (Bisheh). 


\begin{tabular}{|l|l|l|l|}
\hline SIGLO & YACIMIENTO & ESTANCIAS & ESTANQUE \\
\hline IX & RAQQĀDA & $16,6 \times 9,25$ & $106,38 \times 85,10$ \\
\hline$X$ & SABRA-MANȘŪRIYYA & & $130 \times 50$ \\
\hline$X$ & AL-RUMMANIYYA & & $50 \times 28$ \\
\hline X-XI & FAVARA & & \\
\hline XI & QAL'AT B. HAMMĀD & & \\
\hline XI & EL CAIRO & & \\
\hline XI & P. GALIANA & $23,75 \times 14,4$ & $18,2 \times 15,6$ \\
\hline XII & BUHAYYRA & & $41,5 \mathrm{~m}^{2}$ \\
\hline XII & MONTEAGUDO & & $161 \times 136$ \\
\hline XIII & ABŪ FIHR & & $209 \times 80,5$ \\
\hline XIII & ABŪ TAŠFİN & & $200 \times 100$ \\
\hline XIV & ALCÁZAR GENIL & $34 \times 5$ & $121,4 \times 28$ \\
\hline
\end{tabular}

Fig. 4. Estructuras palatinas con estanque de grandes dimensiones 

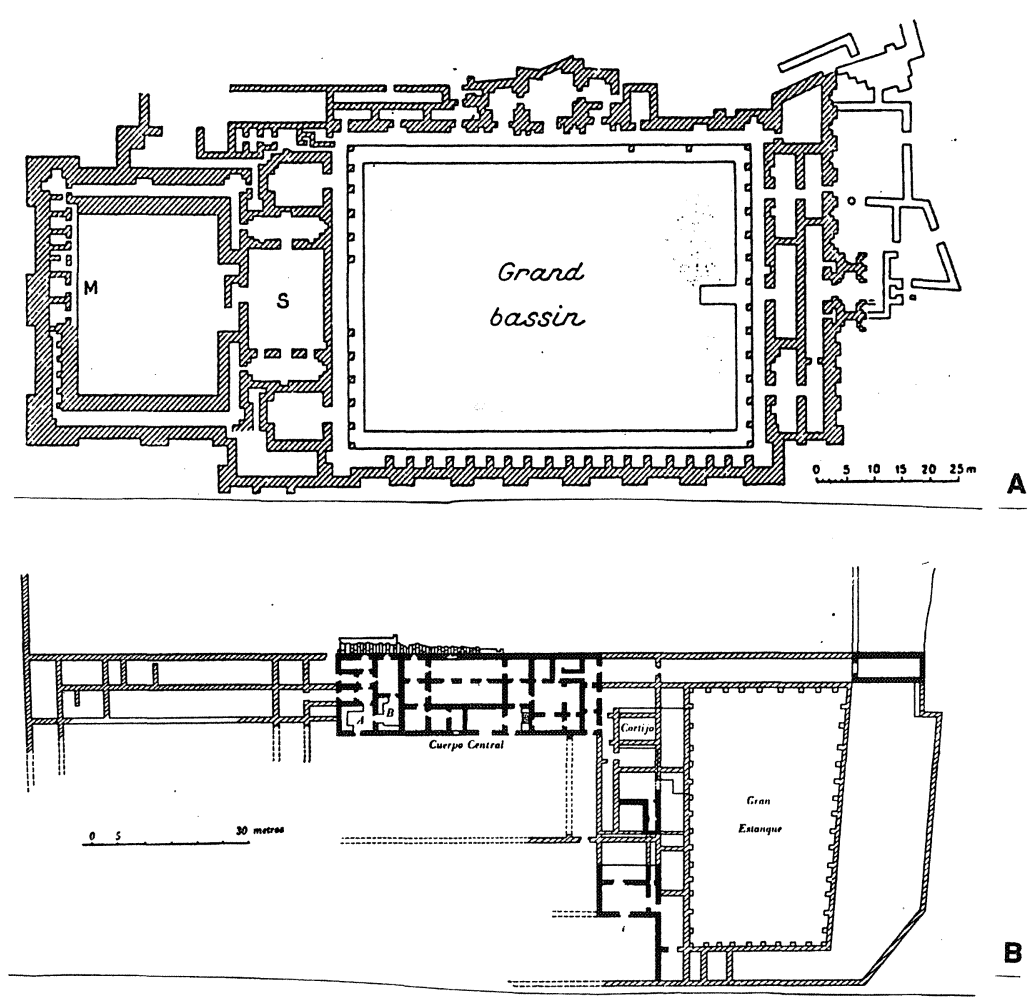

B
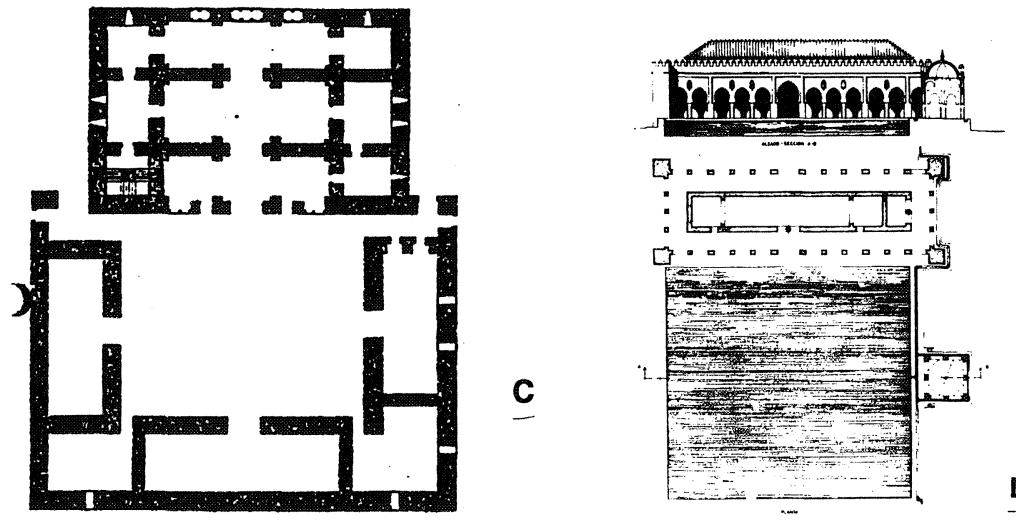

Figura 5a. Dār al-Baḥr, Qal'at Banī Ḥammād (De Beylié).

5b. Almunia al-Rūmmaniyya, Córdoba (Velázquez Bosco).

5c. Palacio Galiana, Toledo (Gómez Moreno).

5d. Palacio de la Buhayra, Sevilla (Manzano Martos). 


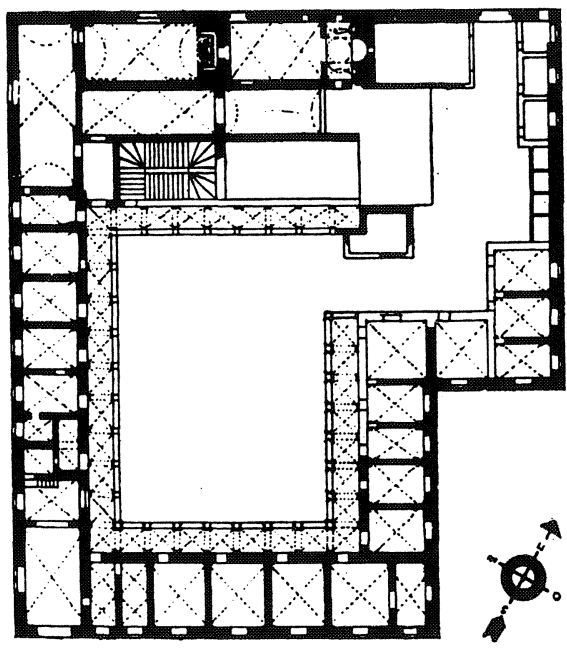

Figura 6a. Planta del palacio de la Favara (Goldschmidt).

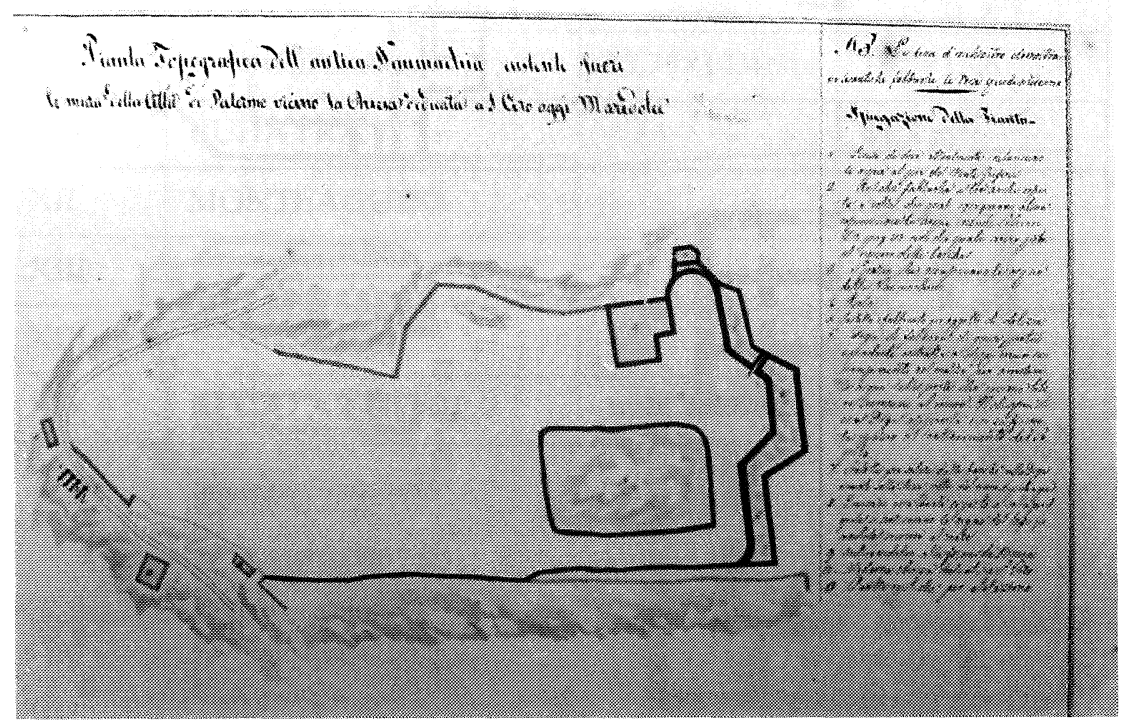

Lámina 2. Planimetría del lago y del palacio del Maredolce o Favara de Palermo a fines del siglo xviII. Conservado en el palacio Abatellis, Palermo. El palacio, situado en la parte superior, tiene tres de sus lados inmersos en el gran lago, en medio de él y frente al palacio se halla la isla. 


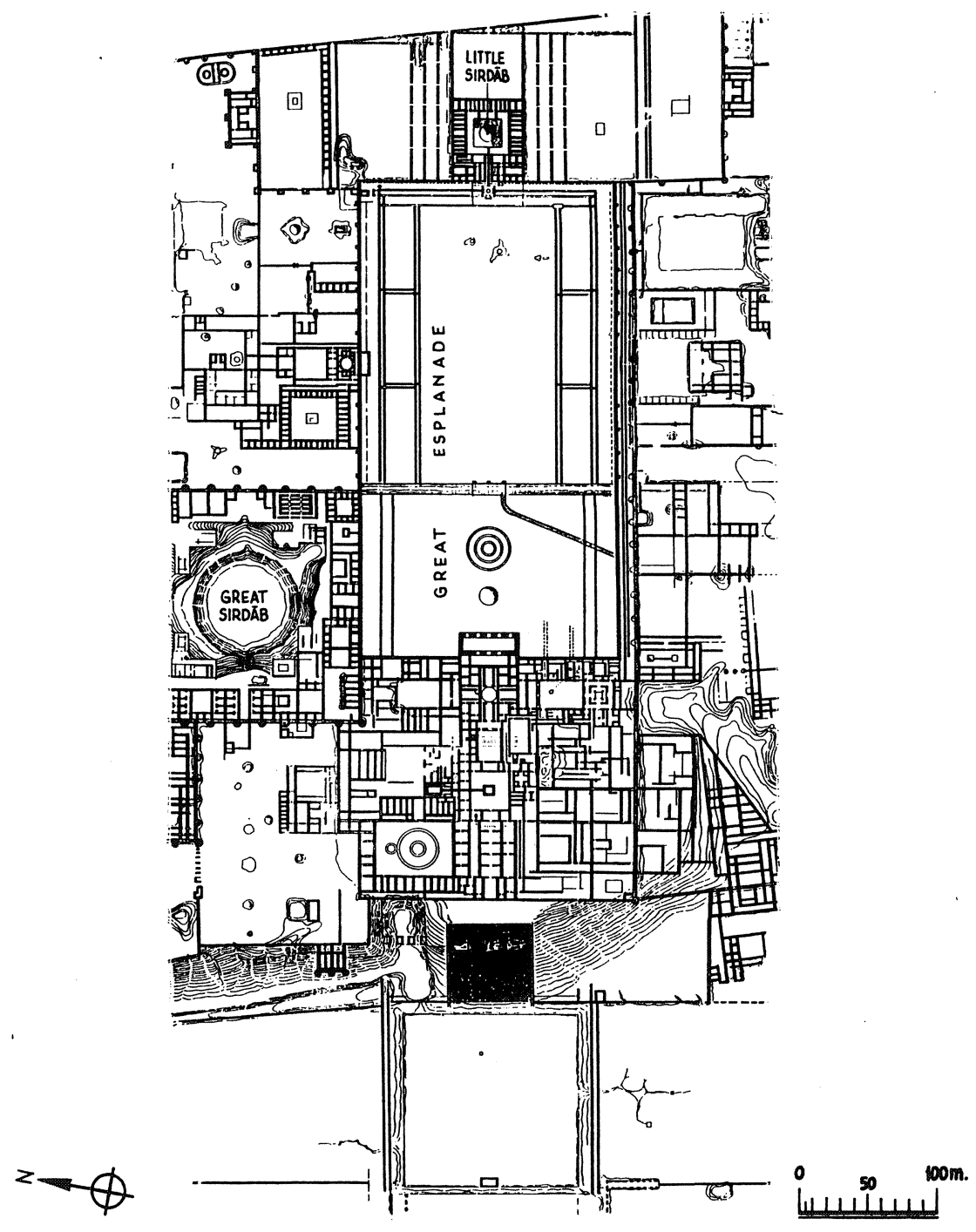

Figura 7. Planta de Balkuwārā, Sāmarrā'. 